\title{
The Developmental Anatomy of Pierce's Disease Symptoms in Grapevines: Green Islands and Matchsticks
}

\author{
Joshua F. Stevenson, Department of Biology and Chemistry, Texas A\&M International University, 5201 University \\ Blvd., Laredo 78041; Mark A. Matthews, Department of Viticulture and Enology, One Shields Ave., University of \\ California, Davis 95616; and Thomas L. Rost, Section of Plant Biology, One Shields Ave., University of California, \\ Davis 95616
}

\begin{abstract}
Stevenson, J. F., Matthews, M. A., and Rost, T. L. 2005. The developmental anatomy of Pierce's disease symptoms in grapevines: Green islands and matchsticks. Plant Dis. 89:543-548.

Symptoms of Pierce's disease were studied in an anatomical context from infected grapevines (Vitis species) collected from field sites within Napa Valley, CA. Two symptoms, green islands and matchsticks, are reported in this study. Green islands formed as a result of incomplete initiation of the phellogen. In regions of the stem where a phellogen and subsequent periderm arose, immediately exterior tissue was cut off, causing it to brown. In regions of the stem where no periderm is formed, the exterior tissues remained green. Consequently, the stem is mottled with both green living epidermis and brown dying epidermis as determined by the presence or absence of an underlying periderm. Matchsticks formed when the leaf lamina separated from the petiole, and the petiole remained attached to the stem. Lamina broke off from the petioles consistently in a fracture zone where xylem from the petiole anastomoses into the five major veins of the leaf. No separation layer was found to explain this pseudoabscission.
\end{abstract}

Pierce's disease (PD) in grapevine is caused by an insect-vectored bacterial infection of Xylella fastidiosa (12). Plants are inoculated with bacteria by xylemfeeding suctorial insects commonly known as sharpshooters (18). The spread of this bacterium, or its products, within a susceptible grapevine leads to xylem blockage characteristic of PD (11). However, once bacteria are introduced into the hydraulic network of the grapevine host, the exact mechanism(s) of pathogenesis is unknown. Possibilities include xylem blockage by bacterial aggregation $(10,21)$, phytotoxins produced by the bacteria $(7,13)$, gels and tyloses produced by the plant that may decrease xylem conductance $(2,6,15)$, programmed cell death (D. Gilchrist, UC Davis, personal communication), or a combination of these factors.

PD is associated with distinctive visible symptoms including leaf "matchsticks" and "green islands". Green islands, or irregular lignification, appear on stems of infected plants in an intermediate zone between the uniformly green stem in apical

Corresponding author: J. F. Stevenson

E-mail: jstevenson@tamiu.edu

Accepted for publication 27 November 2004.

DOI: 10.1094/PD-89-0543

(C) 2005 The American Phytopathological Society regions and the uniformly browned stem in basal regions. In the intermediate zone, patches of both exclusively green and darkened stem can be found, instead of a typical even transition between the two. Matchsticks form when leaf lamina separate and fall off their petioles, while the petioles remain attached to the plant. The petioles then dehydrate and take on a burnt appearance on their distal tip.

In a normal Vitis species stem, the initial periderm is formed within the phloem $(17,20)$. Periderm is the secondary protective tissue that replaces the epidermis; it consists of phellem (cork), phellogen (cork cambium), and if present, a phelloderm (2). As the periderm develops, it cuts off the exterior tissues of the stem causing them to brown. Normally, this process occurs in a continuous layer around the circumference of the stem, giving a uniform surface appearance. Green islands found on the stem are described as the result of incomplete periderm formation and subsequent uneven cane maturation $(2,8)$, although only a single existing report attempts to describe this symptom anatomically (1).

There is no existing information on the development and structure of PD symptomatic matchsticks. Generally, matchsticks are briefly described in papers or extension communications summarizing disease symptoms without any causal investigation $(8,22)$. No previous research could be found beyond the most superficial descriptions.

Due to the recent growing interest in PD as a threat to viticulture in California and other regions, the goal of this paper is to serve as a definitive and accessible resource, for both growers and scientists, on the developmental anatomy of these visual symptoms. These symptoms have long been used as indicators of PD, but few in the field are aware of what causes these phenomena. Although the development of green islands was documented at the turn of the last century (1), updated visual and descriptive evidence may be helpful to other researchers in the field, especially those using green islands as a strict diagnostic tool for the severity of PD susceptibility (A. Krivanek, UC Davis, personal communication). Additionally, anatomical comparisons of periderm formation between Vitis and Muscadinia species may provide insight into the assessment of PD susceptibility or resistance of these groups. Furthermore, the nearly complete void of information pertaining to matchstick formation required that this topic be addressed.

\section{MATERIALS AND METHODS}

Plant samples from Vitis vinifera L. cvs. Sauvignon Blanc and Merlot grapevines were collected from commercial vineyards in Napa Valley, CA. Infected shoots with green islands and matchsticks present were pruned from PD-positive vines. Other labs working with a variety of techniques (i.e., polymerase chain reaction, enzyme-linked immunosorbent assay) verified vine infection with $X$. fastidiosa. Additionally, bacterial populations were observed in the experimental tissues with scanning electron microscopy for other anatomical studies. Stem samples of Muscadinia rotundifolia cv. Cowart were collected from greenhouse plants grown at the University of California, Davis.

Plant tissue samples were dissected, fixed in formalin-acetic acid-ethanol (FAA), and dehydrated through an ethanol series (19). The samples were then infiltrated with Hemo-De (Fisher Scientific, Hampton, NH) and subsequently Paraplast 
Extra paraffin (Fisher Healthcare, Houston, TX) using a Leica TP 1020 automatic tissue processor, embedded with a Leica EG 1160 paraffin embedding center (Leica Microsystems, Bannockburn, IL), and sectioned at $10 \mu \mathrm{m}$ with a Microm HM 304E rotary microtome (Microm, Walldorf, Germany). Sections were stained following the Johansen's safranin and fast

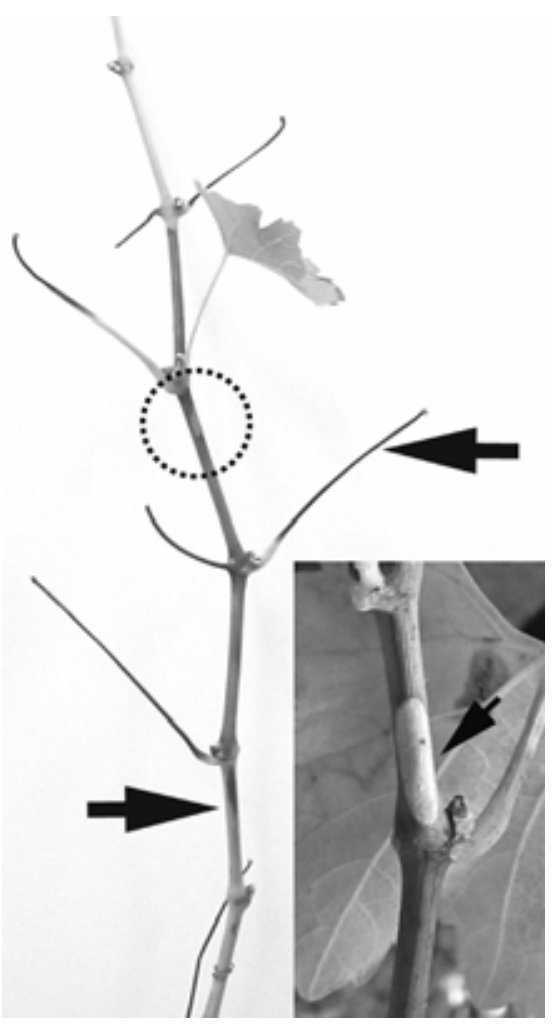

Fig. 1. Grapevine shoot with visible advanced Pierce's disease symptoms. Left-pointing arrow indicates a matchstick, right-pointing arrow indicates a region of stem with both green and brown epidermis. Dotted circle indicates location of a green island, similar to that highlighted in the inset image. green protocol (19). Prepared slides were observed with an Olympus Vanox-AHBT compound light microscope (Hitachi HighTechnologies America, San Francisco, CA), and images were captured with a Pixera 600ES digital camera (Pixera Corporation, Los Gatos, CA).

\section{RESULTS}

Green islands and matchsticks were studied to determine the anatomical cause of these PD symptoms (Fig. 1). Green islands remain on the stem surface of Vitis species grapevines infected with PD as a result of incomplete development of the periderm. In normal development, a stem will transform from an immature state possessing a green cortex, an epidermis and lacking any periderm (Fig. 2), to a stem with a collapsed, brownish epidermis created by the developing periderm from an active phellogen (the cork cambium, a lateral meristem that creates the periderm [2]) (Fig. 3). In an uninfected green stem, no subepidermal periderm development is present, and the cells of the cortex and epidermis are healthy and turgid (Fig. 2). The primary phloem is made up of parenchymatous cells (including sieve elements, companion cells, and axial parenchyma) bounded by a phloem fiber cap to the exterior; whereas the secondary phloem consists of alternating bands of parenchymatous tissue and fibers. A young, brown-colored stem (Fig. 1) is created by the initiation of periderm development, including a complete ring of phellogen forming in the secondary phloem, producing phellem to the exterior and a phelloderm to the interior (Fig. 3). As the internal periderm forms, the exterior tissues (some secondary phloem, primary phloem, cortex, and epidermis) are cut off from internal sources of water and nutrition and begin to collapse and die.
Periderm development in plants infected with PD is incomplete and results in certain portions of the stem circumference remaining green, while other portions turn brown coupled with periderm formation. Instead of a complete ring of phellogen forming in the phloem, irregular patches of phellogen are activated incompletely around the stem circumference (Fig. 4). In regions where the phellogen develops, the exterior tissues brown, but in regions where no phellogen develops, exterior tissues remain green. In the transition area between green and brown stem (on the border of a green island), the boundary of the developing periderm exists (Fig. 5). The initiation of the phellogen appears to only slightly precede the collapse of cortical parenchyma and the browning of exterior tissues. With closer inspection, the activation of the phellogen may occur just interior to the primary phloem, or even interior to the oldest fiber layer of the secondary phloem (Fig. 6). The discrete segments of the developing phellogen can remain intact across regions of proliferation tissue within the secondary phloem (Fig. 6), and also across the expansion tissue of dilatated rays (Fig. 7).

The initial formation of the phellogen does not occur in the same tissues in all grapevines. Whereas the first periderm arises within the phloem of Vitis vinifera, it arises from the subepidermal region in Muscadinia rotundifolia (Fig. 8).

Matchsticks on grapevines infected with PD are a result of a pseudoabscission of the leaf blade from the distal end of the petiole. No evidence of a separation zone was found at the distal end of petioles either prior to pseudoabscission or post-pseudoabscission where the leaf lamina was previously attached. Petioles appeared to be simply fractured at the petiole-lamina junction, and no cell expansion or protective layer was found in

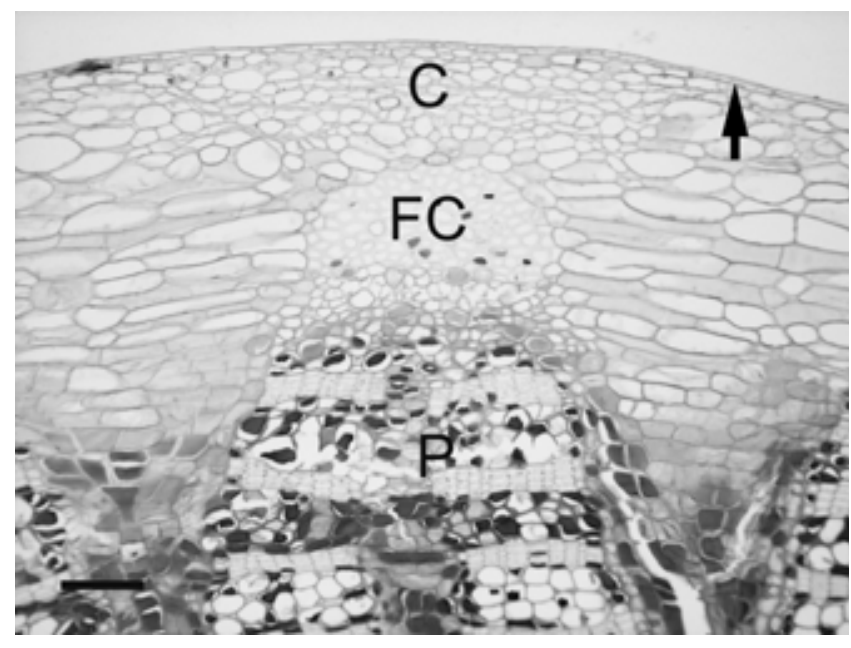

Fig. 2. Transverse section through control grapevine stem (uninfected) showing development prior to initiation of phellogen. $\mathrm{C}=$ cortex, $\mathrm{FC}=$ phloem fiber cap, $\mathrm{P}=$ phloem, arrow indicates healthy green epidermis. Scale bar $=0.1 \mathrm{~mm}$.

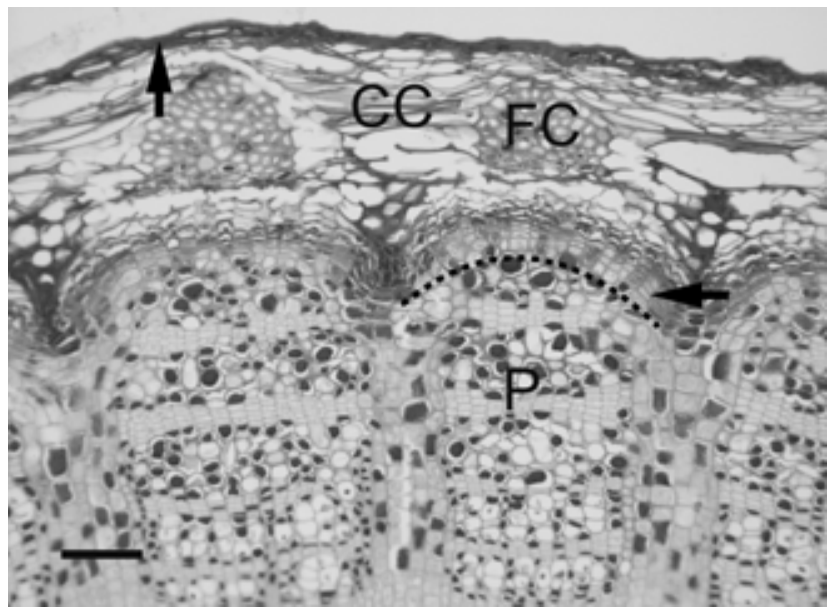

Fig. 3. Transverse section through control grapevine stem (uninfected) showing development following initiation of phellogen. $\mathrm{CC}=$ collapsed cortical cells, $\mathrm{FC}=$ phloem fiber cap, $\mathrm{P}=$ phloem, dotted line is internal boundary of the developing periderm, vertical arrow indicates dead epidermis, horizontal arrow indicates phellogen. Scale bar $=0.1 \mathrm{~mm}$. 
this region that accompanies true leaf abscission.

A leaf lamina can still be attached to the petiole with significant leaf scorching and tissue necrosis across the majority of the leaf (Fig. 9). A fracture zone is predictable at the distal end of the petiole in the region where xylem anastomoses from the arrangement of a circle of bundles in the petiole to the palmate venation in the lamina. As leaf necrosis encroaches on the leaf-petiole junction, a fracture between leaf and petiole forms (Fig. 10). This fracture occurs rapidly, and the lamina is detached from the petiole without the formation of a separation zone typically found with leaf abscission (Fig. 11). The petiole tissue, now detached from the lamina, begins to dehydrate, usually before a wound periderm can form (Fig. 12). As dehydration occurs basipetally, the petiole takes the appearance of a burnt matchstick (Fig. 13). Rarely, a wound periderm will form at the distal end of the petiole following pseudoabscission of the lamina (Fig. 14). The formation of the wound periderm prevents dehydration of the petiole, and tissues basal to the protective barrier remain turgid and healthy. This results in a petiole with detached lamina, but without the extreme dehydration, no burnt matchstick is created.

Xylem occlusions are present in the fracture zone (Fig. 15). Typically, the occlusions consisted of accumulations of bacteria and gel, and occasionally tyloses.

\section{DISCUSSION}

The development of green islands and matchsticks are visible, external symptoms that are indicators of Pierce's disease of grapevines (22). Although these symptoms are not always found with all PD-positive plants, especially in the early stages of the disease, they are commonly used as a distinctive and characteristic symptom of the disease in the field.

In normal stem development, a cork cambium, or phellogen, is formed in the same internode of the initiation of the vascular cambium (9) to 20 or more internodes basal to the internode containing the latest initiation of vascular cambium (16). In healthy plants, a phellogen forms a complete ring around the stem at the depth of the primary phloem or greater. An active phellogen produces cork, or phellem, toward the outside, and a much lesser amount of phelloderm toward the inside (17). Phellogen, phellem, and phelloderm collectively comprise the periderm. The formation of periderm results in the separation of the epidermis, cortex, and pri-

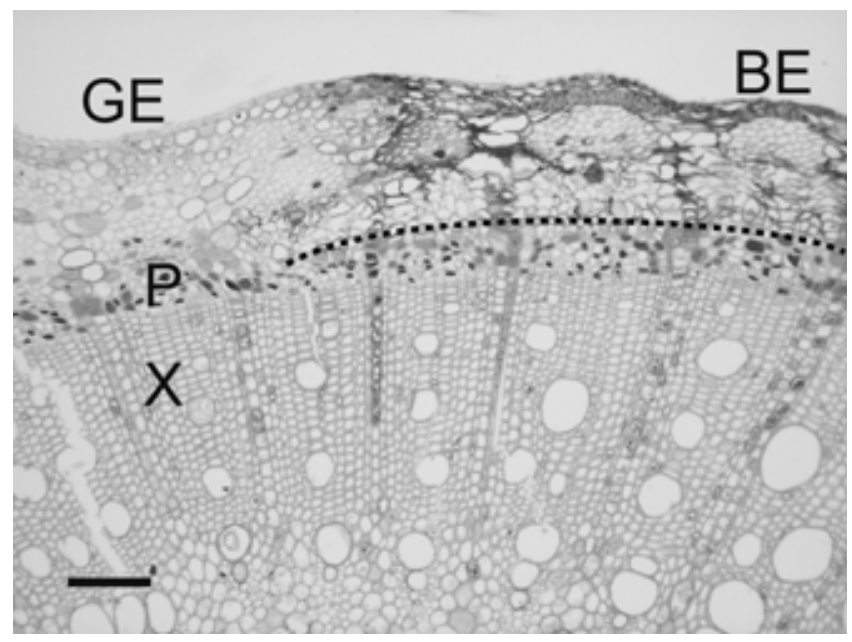

Fig. 4. Transverse section through Pierce's disease infected grapevine stem showing overview of the boundary between green and brown epidermis that creates a green island. $\mathrm{GE}=$ region of green epidermis, $\mathrm{BE}=$ region of brown epidermis, $\mathrm{X}=$ xylem, $\mathrm{P}=$ phloem, dotted line indicates boundary of incomplete phellogen initiation. Scale bar $=0.25 \mathrm{~mm}$.

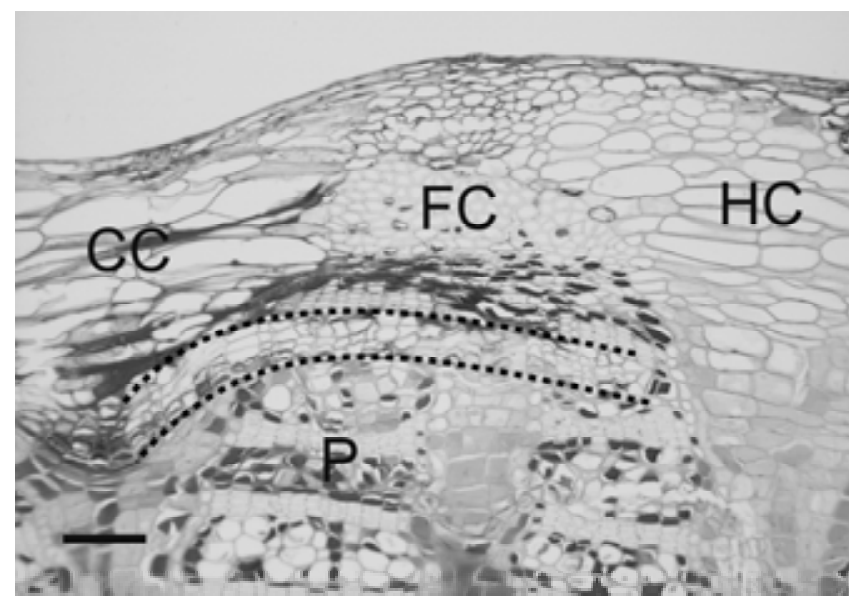

Fig. 5. Transverse section through Pierce's disease infected grapevine stem showing detail of transition area between the brown epidermis and green epidermis that creates a green island. $\mathrm{CC}=$ collapsing cortex, $\mathrm{HC}=$ healthy cortex, $\mathrm{FC}=$ phloem fiber cap, $\mathrm{P}=$ phloem, dotted line delimits developing phelloderm. Scale bar $=0.1 \mathrm{~mm}$.

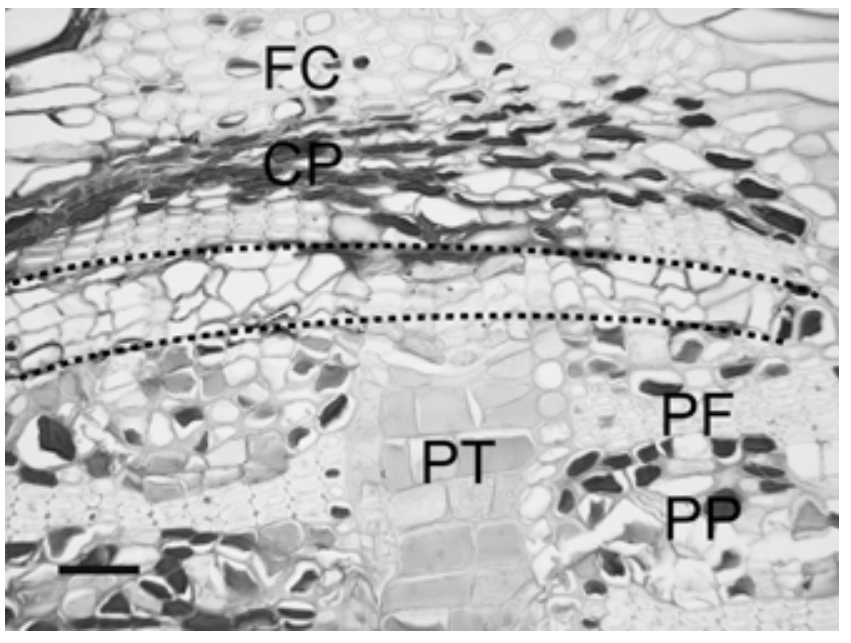

Fig. 6. Transverse section through Pierce's disease infected grapevine stem showing initiation of phellogen within the phloem. $\mathrm{FC}=$ phloem fiber cap, $\mathrm{CP}=$ collapsed phloem, $\mathrm{PT}=$ proliferation tissue, $\mathrm{PF}=$ phloem fibers, $\mathrm{PP}$ = phloem parenchyma, dashed lines delimit development of phelloderm. Scale bar $=0.05 \mathrm{~mm}$.

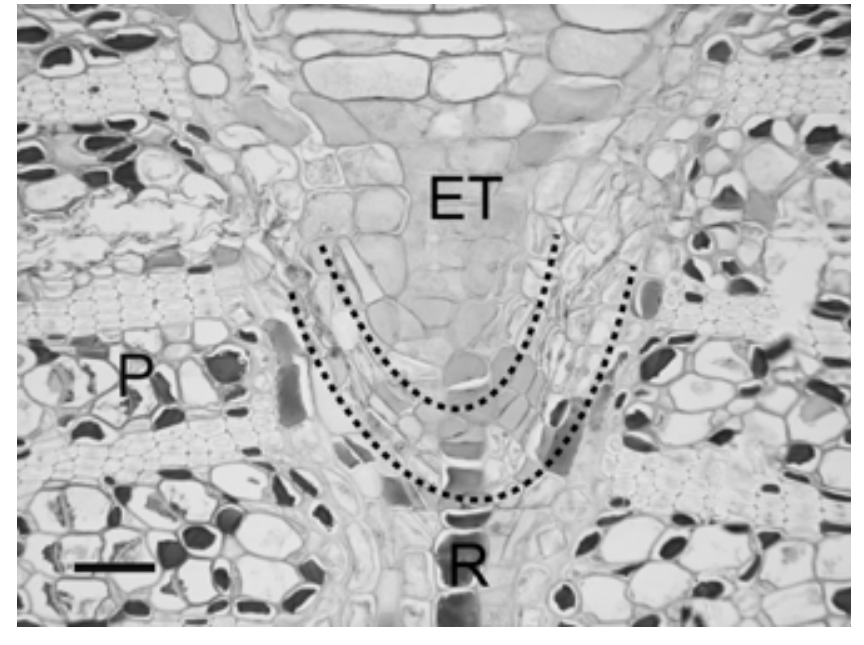

Fig. 7. Transverse section through Pierce's disease infected grapevine stem showing initiation of phellogen within a dilatated ray. $\mathrm{P}=$ phloem, ET = expansion tissue, $\mathrm{R}=$ ray. Scale bar $=0.05 \mathrm{~mm}$. 
mary phloem from the secondary phloem and other vascular elements of the main axis. As the cortex and primary phloem become isolated from the conducting system by the periderm, these tissues die. Consequently, the dead outermost layers form the brown covering of a mature cane during its first year of growth.

Green islands are created when the periderm is activated in irregular patches around the stem circumference. In PD plants, the phellogen and consequent cells are produced discontinuously, which results in areas of the epidermis and cortex that are not segregated from the main stem and remain vital and green. The interspersed patches of green, juxtaposed with patches of brown, create green islands. The discontinuous phellogen may arise within the phloem proper, or within dilatated phloem. If the initial phellogen arises within the phloem proper, it is usually found interior to the primary phloem, or even interior to bands of secondary phloem fibers. As the stem diameter increases with growth, the phloem may divide anticlinally to accommodate the increasing girth, called dilatation (3). Dilatation tissue can be subdivided into proliferation tissue, found within axial parenchyma, and expansion tissue, found within phloem rays. The phellogen can arise within the proliferation tissue of the secondary phloem, or if the initial phellogen arises within the expansion tissue, it usually follows the contour of the boundary between the dilatated ray and the phloem proper to the point of the undilatated phloem ray. The cortex and epidermis are affected very soon after initiation of the periderm, and epidermal browning is very closely related to the absence of periderm formation immediately internal to it. This allows for sharp delimitation between patches of green and brown on the stem surface.
Green islands are also regularly described as irregular lignification of the stem. This is a misnomer based on the field jargon of lignification referring to visible maturation of the stem resulting from periderm formation. Lignification, as a botanical term, refers to the deposition of lignin within cell walls, typically associated with sclerenchymatous cell types (i.e., xylem, extraxylary fibers, etc.) (3). The periderm of grapevine generally consists of parenchymatous cells with no lignified walls, and as such, lignification has no place in describing the development of this tissue, unless it is being used in the context of the developing xylem in the central region of the stem. It must be noted, however, that lignified phloem fibers will be present on, or near, the stem surface to some degree in older stems as newly formed phellogens created in subsequent seasons are activated deeper within the

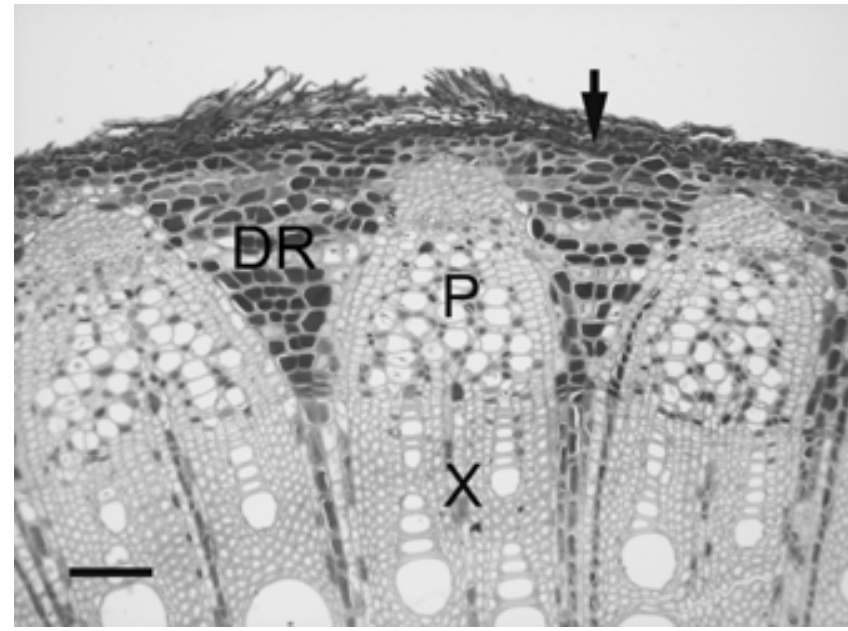

Fig. 8. Transverse section through an uninfected muscadine grapevine stem showing subepidermal development of phelloderm. $\mathrm{P}=$ phloem, $\mathrm{X}=$ xylem, $\mathrm{DR}=$ dilatated ray, arrow indicates phellogen. Scale bar $=0.1 \mathrm{~mm}$.

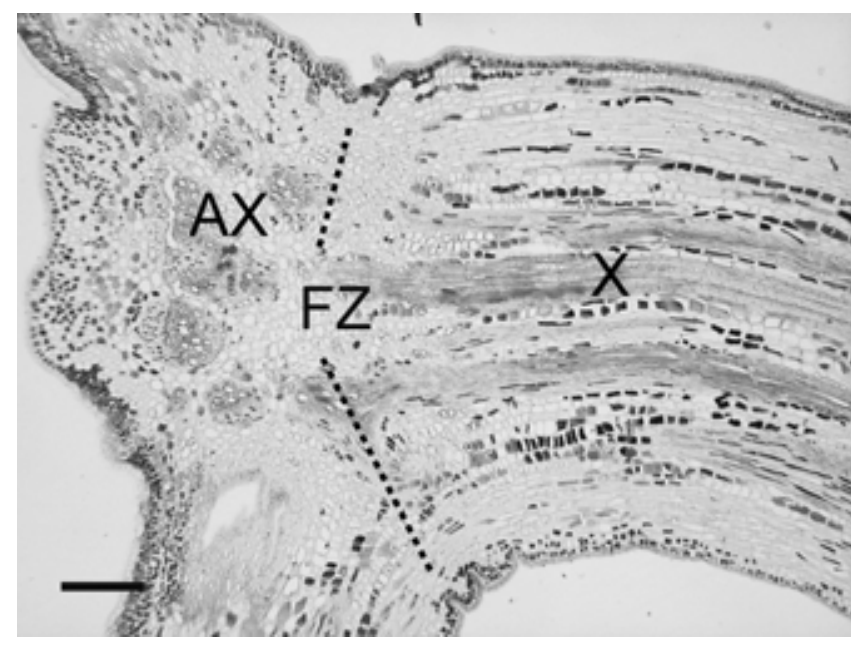

Fig. 9. Longitudinal section through distal end of a petiole attached to a Pierce's disease (PD) symptomatic leaf. PD symptoms are not visible within field of view. $X=$ xylem, $A X=$ anastomosis of xylem to the five major veins of the lamina, $\mathrm{FZ}=$ fracture zone. Scale bar $=0.25 \mathrm{~mm}$.

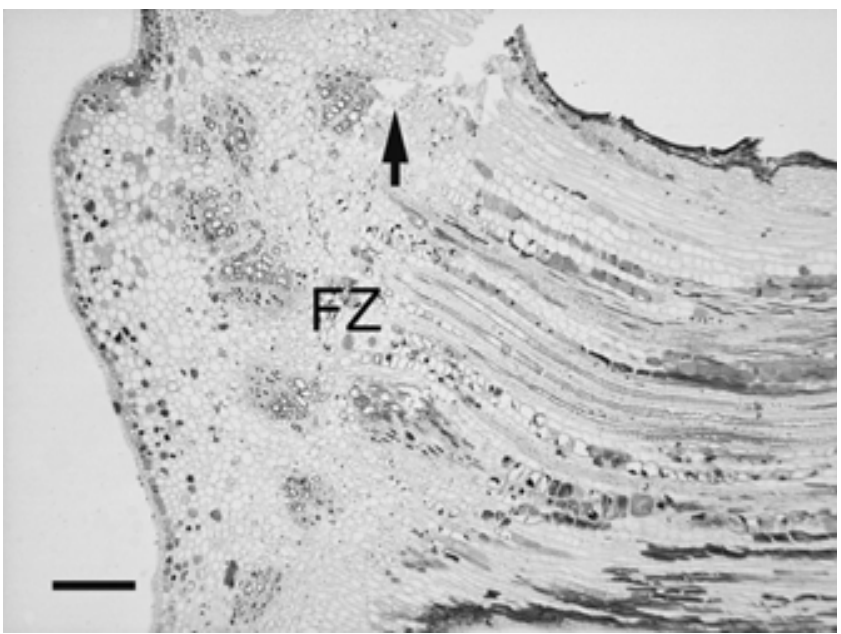

Fig. 10. Longitudinal section through distal end of a petiole attached to a Pierce's disease-symptomatic leaf showing initial separation between lamina and petiole. $\mathrm{FZ}=$ fracture zone, arrow indicates partial fracture. Scale bar $=0.25 \mathrm{~mm}$.

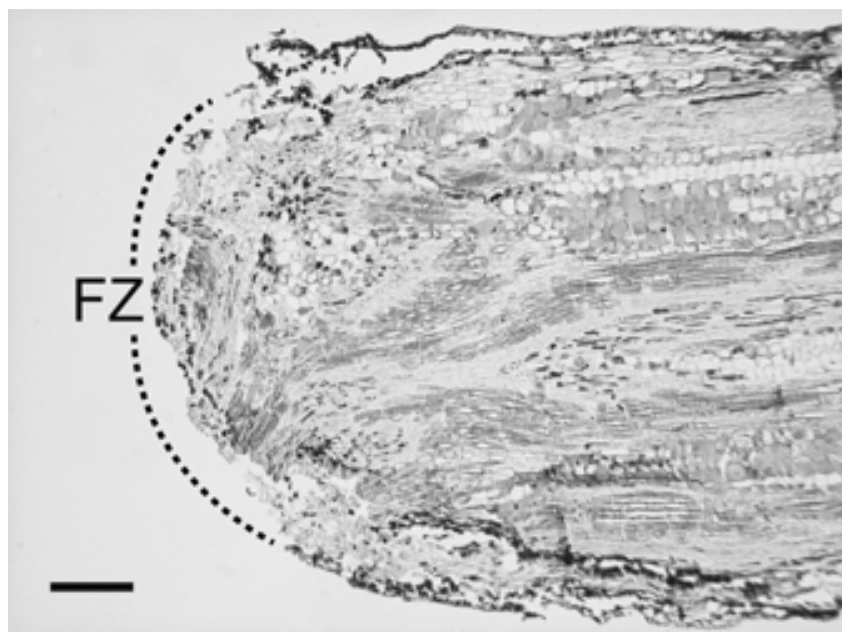

Fig. 11. Longitudinal section through distal end of a petiole previously attached to a Pierce's disease-symptomatic leaf showing complete detachment of lamina from petiole. $\mathrm{FZ}=$ fracture zone. Scale bar $=0.25 \mathrm{~mm}$. 
phloem causing older phloem to be pushed to the stem surface.

No consistent patterns were found either in the position of green islands on the stem, or between green islands and the amount of xylem occlusion proximal to a green island. Regions of green islands could be near xylem that was densely occluded with tyloses or near xylem that was completely unoccluded. More often than not, green islands were observed near the nodes and on the lateral surfaces of the stem (i.e., aligned with the plane of the petioles), but were possible anywhere around the stem circumference.

As stem maturation has been linked to plant water status (14), drought stress may further exacerbate any effects of PD on the development of green islands. It is unknown whether green island formation on the surface of the stem is due to delayed development beneath the green segment, or due to advanced development in the brown areas that surround the green segment. If the brown areas surrounding the green island are a result of accelerated periderm development as is associated with drought stress (14), this may be more evidence that drought stress due to vessel occlusion is a significant contributing factor in the pathology of the disease.

The periderm arises in different tissues in the genera Vitis and Muscadinia. Vitis spp. produce a deep-seated phellogen, whereas Muscadinia spp. produce a subepidermal phellogen (16). This is an important factor to consider for researchers using visible periderm formation as an indicator of PD susceptibility and resistance (A. Krivanek, UC Davis, personal communication). Although this assessment technique may be justified when comparing PD affliction within Vitis, comparisons of cane maturation between Vitis and Mus- cadinia would have a fundamental confounding element. Muscadinia spp. are generally considered to be very resistant to $\mathrm{PD}$, and it is unknown if cane maturation within this group can be affected by $X$. fastidiosa inoculation. However, should Muscadinia sources be involved in future transgenic or breeding work designed to confer PD resistance, evaluation of the resultant plants with cane maturation indices should take the source tissue for periderm formation into consideration.

Matchsticks are found when the leaf lamina falls from the subtending petiole, leaving the petiole alone attached to the stem. Generally, leaf scorching and necrosis proceed from the leaf margins toward the base of the lamina to the petiole, and then the leaf separates (5). Before tissue death occurs in the petiole-lamina junction, a fracture arises in the most distal end of the petiole where the circularly arranged

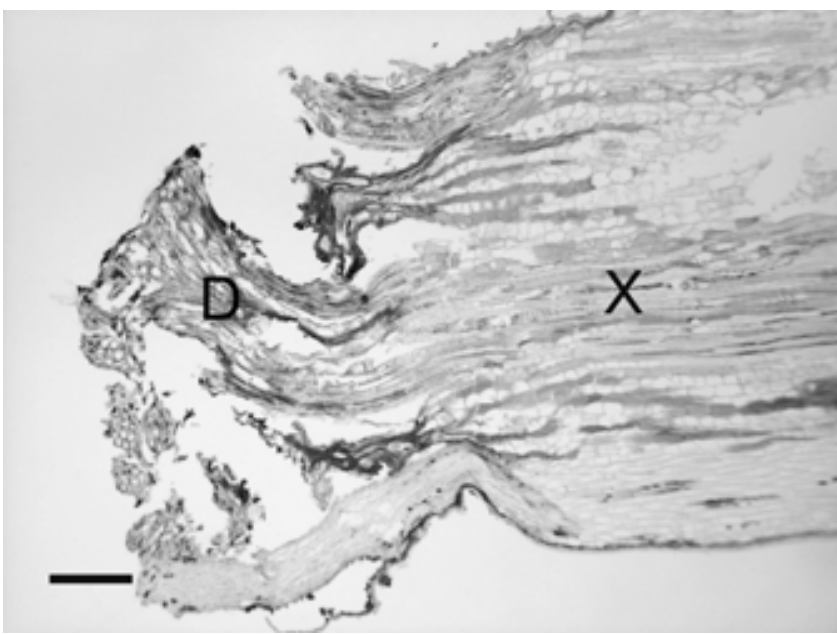

Fig. 12. Longitudinal section through distal end of a petiole previously attached to a Pierce's disease-symptomatic leaf showing initial basipetal dehydration. $\mathrm{D}=$ dehydrated tissue, $\mathrm{X}=$ xylem. Scale bar $=0.25 \mathrm{~mm}$.

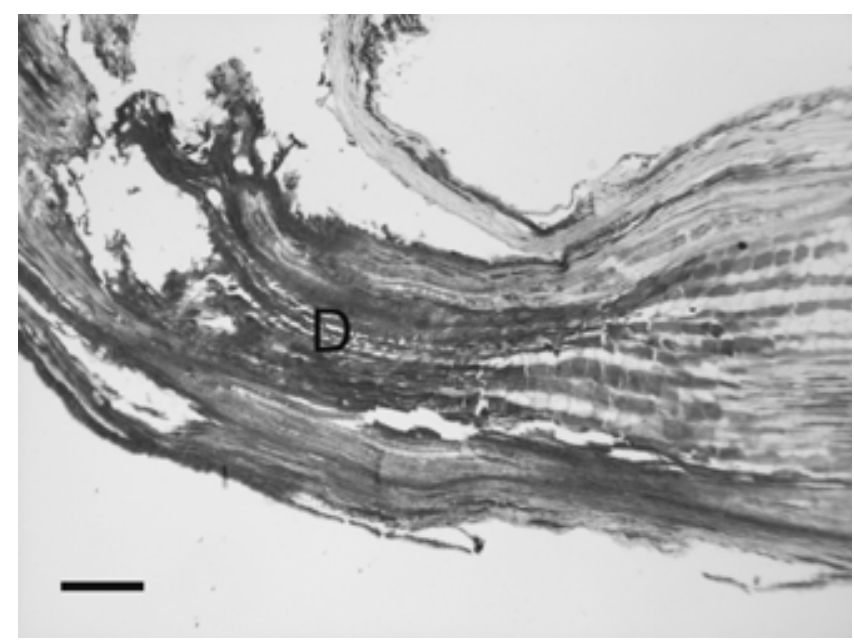

Fig. 13. Longitudinal section through distal end of a petiole previously attached to a Pierce's disease-symptomatic leaf showing advanced basipetal dehydration and appearing as a matchstick. $\mathrm{D}=$ dehydrated tissue. Scale bar $=0.25 \mathrm{~mm}$

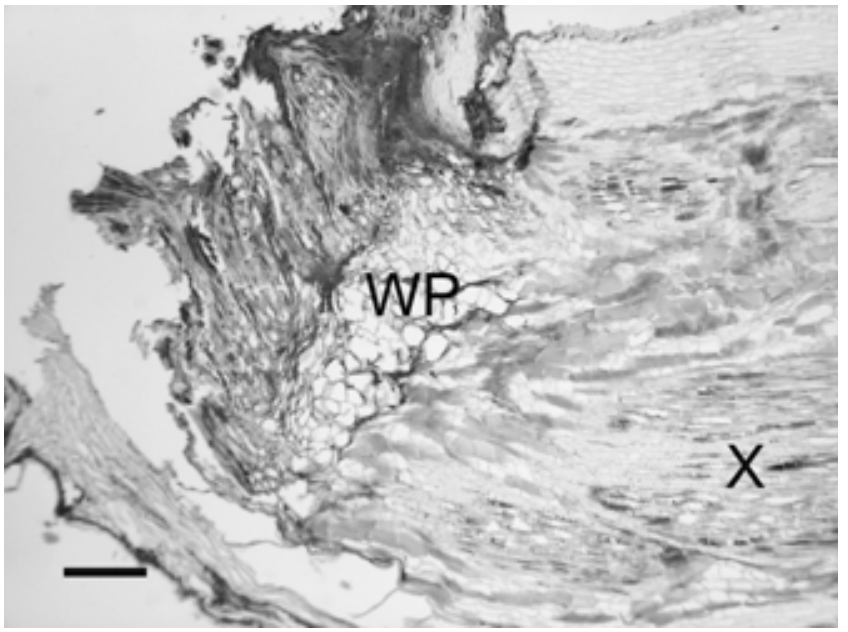

Fig. 14. Longitudinal section through distal end of a petiole previously attached to a Pierce's disease-symptomatic leaf showing rare formation of wound periderm arresting basipetal dehydration. $\mathrm{WP}=$ wound periderm, $\mathrm{X}$ $=$ xylem. Scale bar $=0.25 \mathrm{~mm}$.

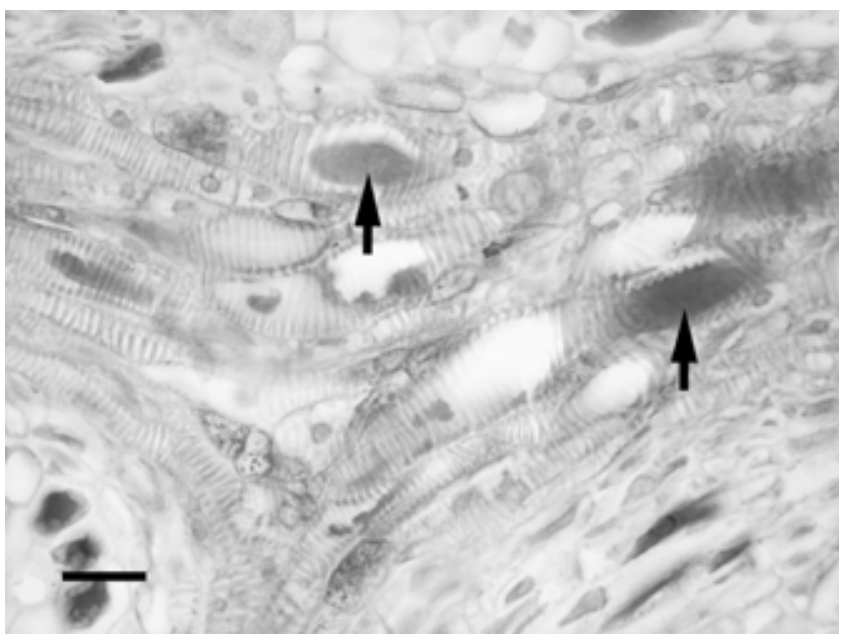

Fig. 15. Longitudinal section through the leaf-petiole junction of a severely scorched leaf showing bacteria-gel conglomerations in tracheary elements of the anastomosing xylem. Arrows indicate bacteria-gel conglomerations. Scale bar $=0.025 \mathrm{~mm}$. 
vascular bundles of the petiole anastomose into the five major veins of the lamina. This fracture, we are calling pseudoabscission, may be created by a structural weakness that consistently allows the lamina to break from the petiole in this area. After this pseudoabscission, the petiole dehydrates and blackens in a basipetal direction giving the appearance of a matchstick. The petiole may eventually completely dehydrate and blacken all the way to the petiole-stem junction. Rarely, the petiole tissue exposed by the pseudoabscission of the lamina will produce a wound periderm to protect the remainder of the petiole from dehydration. When this occurs, tissue interior to the wound periderm remains turgid and healthy, and only the very distal portion of the petiole blackens.

No evidence was found of a separation zone consistent with typical leaf abscission (3) that would cause a PD symptomatic leaf to detach from the petiole. Conspicuous cell division or cellular breakdown was absent preceding terminal leaf pseudoabscission. Leaves appear to simply break off the petiole after becoming significantly scorched. A working hypothesis developed early in this study proposed that occlusions in petioles associated with PD may induce the formation of a true separation zone at the distal end of the petiole, the opposite end of the petiole from which normal abscission occurs. Regular leaf abscission is commonly accompanied by the initial symptom of tylose development within the tracheary elements of the separation zone (4). It was initially proposed that perhaps the development of abscission-associated symptoms in an unusual location could trigger the developmental pathways that cause normal leaf abscission to also occur in an unusual location. Although vessel occlusions were present in the fracture zone, no separation layer was created, and consequently, no support for this proposal was found.

Green islands and matchsticks can be described anatomically, but the underlying mechanisms that cause their formation remain unknown. It is unclear why green islands temporarily persist in certain portions of the stem and not in others. No correlations between green islands and either stem anatomy or the presence of other PD symptoms were found. Further study is required to examine a potential link between the location of green islands with proximal $X$. fastidiosa populations or bacteria-produced substances. As green islands appear to be areas of the stem that retain juvenile characters, perhaps growth regulating hormones play a role. Additionally, the development of green islands needs to be examined in the context of other environmental factors such as water stress. Matchsticks caused by pseudoabscission of lamina from petioles show no symptoms in the fracture zone prior to the separation event. Although pseudoabscission does not occur until leaf scorching is significant, dieback was not evident immediately within the fracture zone. Further research is required to perhaps link this phenomenon with either bacteria-produced substances or more subtle structural changes than those normally associated with organ abscission.

\section{ACKNOWLEDGMENTS}

Funding for this research was provided by the California Department of Food and Agriculture, Agreement No. 01-0712. We thank M. Caroline Roper of the Bruce Kirkpatrick lab for assistance in locating field samples.

\section{LITERATURE CITED}

1. Butler, O. 1910. Observations on the California vine disease. Torrey Botanical Club Mem. 14:111-153.

2. Esau, K. 1948. Anatomic effects of the viruses of Pierce's disease and phony peach. Hilgardia 18:423-482.

3. Esau, K. 1977. Anatomy of Seed Plants. 2nd ed. John Wiley \& Sons, New York.

4. Fahn, A. 1990. Plant Anatomy. 4th ed. Butterworth Heinemann, Boston.

5. Flaherty, D. H., Christensen, L. P., Lanini, W. T., Marois, J. J., Phillips, P. A., and Wilson, L. T. 1992. Grape Pest Management. Univ. Calif. Div. Agric. Natl. Resour., Publ. 3343.

6. Fry, S. M., and Milholland, R. D. 1990. Response of resistant, tolerant, and susceptible grapevine tissues to invasion by the Pierce's disease bacterium, Xylella fastidiosa. Phytopathology: 80:66-69.

7. Goodwin, P. H., Devay, J. E., and Meredith, C. P. 1988. Roles of water stress and phytotoxins in the development of Pierce's disease of the grapevine. Physiol. Mol. Plant Pathol. 32:1-15.

8. Hewitt, W. B., Frazier, N. W., Jacob, H. E., and Freitag, J. H. 1942. Pierce's disease of grapevines. Univ. Calif. Agric. Exp. Stn. Circ. 353:1-32

9. Hoefert, L. L., and Gifford, E. M. 1967. Grapevine leafroll virus - History and anatomic effects. Hilgardia 38:403-426.

10. Hopkins, D. L. 1981. Seasonal concentration of the Pierce's disease bacterium in grapevine stems, petioles, and leaf veins. Phytopathology 71:415-418.

11. Hopkins, D. L. 1989. Xylella fastidiosa: Xylem-limited bacterial pathogen of plants. Annu. Rev. Phytopathol. 27:271-290.

12. Hopkins, D. L., and Mollenhauer, H. H. 1973. Rickettsia-like bacterium associated with Pierce's disease of grapes. Science 179:298300.

13. Lee, R. F., Raju, B. C., Nyland, G., and Goheen, A. C. 1982. Phytotoxin(s) produced in culture by the Pierce's disease bacterium. Phytopathology 72:886-888.

14. Matthews, M. A., Anderson, M. M., and Schultz, H. R. 1987. Phenologic and growth responses to early and late season water deficits in Cabernet franc. Vitis 26:147-160.

15. Mollenhauer, H. H., and Hopkins, D. L. 1976. Xylem morphology of Pierce's diseaseinfected grapevines with different levels of tolerance. Physiol. Plant Pathol. 9:95-100.

16. Mullins, M. G., Bouquet, A., and Williams, L. E. 1992. Biology of the Grapevine. Cambridge University Press, Cambridge, UK.

17. Pratt, C. 1974. Vegetative anatomy of cultivated grapes -- A review. Am. J. Enology Vitic. 25:131-150.

18. Purcell, A. H., and Finlay, A. H. 1979. Evidence for noncirculative transmission of Pierce's disease bacterium by sharpshooter leafhoppers. Phytopathology 69:393-395.

19. Ruzin, S. E. 1999. Plant Microtechnique and Microscopy. Oxford University Press, New York.

20. Srivastava, L. M. 1964. Anatomy, chemistry, and physiology of bark. Int. Rev. For. Res. 1:204-277.

21. Tyson, G. E., Stojanovic, B. J., Kuklinski, R. F., DiVittorio, T. J., and Sullivan, M. L. 1985. Scanning electron microscopy of Pierce's disease bacterium in petiolar xylem of grape leaves. Phytopathology 75:264-269.

22. Varela, L. G., Smith, R. J., and Phillips, P. A. 2001. Pierce's Disease. Univ. Calif. Div. Agric. Natl. Resour., Publ. 21600. 